The Atom

By Sir George Thomson. (Home University Library of Modern Knowledge, 145.) Third edition. Pp. viii + 196. (London: Oxford University Press, 1947.) 5s. net.

THIS is neither a text-book nor a 'popular' work, but a book of genuine educational value, in which present knowledge of atomic and nuclear physics is simply but clearly set forth, backed by the historical perspective of earlier ideas, and looking forward to the resolution of present difficulties by further experimental and theoretical development of the subject.

The writing of such a book demands nice judgment and strong determination to hold the balance between facts and theories, and to give no more than proper prominence to those parts of the subject that catch the imagination of the amateur. Sir George Thomson, as in previous editions of the book, has done this admirably and has given, in eighteen short chapters, a remarkably complete outline of modern knowledge of atoms and the electrons and nuclei that are their constituent parts. He never forgets that atoms are fundamental to chemistry as well as to physics, and the chapters on crystal structure, "The Atom in Chemistry" and "The Electron in Chemistry", are among the best in the book.

"The Atom", though quite an elementary book, deserves and indeed demands careful reading. Like the others in this series, it is meant for those who are prepared to think as well as to read. The thoughtful reader will not be satisfied with all the explanations of atomic phenomena that are offered; that is as it should be, for there are plenty of unsatisfying features in current theories. Sir George himself does not hesitate, on occasion, to envisage the overthrow of the views he is expounding; for example, he ends his discussion of the inherent limitations of physical measurement by speculating on "a probe more delicate than an electron", immune from its wave. like properties that he himself has done so much to establish and to use.

P. B. M.

\section{Radio Data Charts}

A Series of Forty-four Abacs providing most of the Essential Data required in Receiver Design. By Dr. R. T. Beatty. Revised by J. McG. Sowerby. Fourth edition, second impression. Pp. 93. (London: Iliffe and Sons, Ltd., 1947.) 7s. 6d. net.

\section{$\mathrm{T}$} HESE charts present in nomogram form the solution to many of the problems met with in the design of radio receivers and similar apparatus. The explanatory text accompanying each chart is brief but clear, and not only gives the formula upon which the chart is based but also provides a general background to the problem. The method of use of each chart is fully explained by means of a key and is illustrated by examples.

In this fourth edition five new charts have been added. One enables the frequency response of single tuned and band-pass circuits to be determined; another gives the coupling coefficient of intermediate frequency transformers; and a third the resonant impedance of a quarter-wave line. The other two are concerned with the design of resistance-coupled amplifiers. Of the remaining charts, five cover the interrelation between inductance, capacity and frequency in resonant circuits over a wide range of values and another group deals with the design of radio-frequency coils, including the effect of screening cans. Assistance in the design of mains transformers and chokes, output transformers, transmission lines and resistance attenuators is also provided. Data on the D.C. resistance of wires, the power dissipated by a resistance and the reactance of coils and condensers, together with scales for the conversion of frequency to wave-length and ratio to decibels, complete this comprehensive collection of 'abacs'.

The main features of this volume which commend it to the radio engineer are the ease and speed with which design problems can be solved and the way in which the effect of changes in the values of the parameters involved can be readily determined.

B. G. P.

\section{Modern Magnetism}

By Prof. L. F. Bates. Second edition, revised and enlarged. Pp. xi+440. (Cambridge: At the University Press, 1948.) 25s. net.

RATES'S "Modern Magnetism", first published in 1939 , is widely appreciated as a general survey in which adequate attention is given to the experimental side. In preparing a second edition, the author's aim was that it should be reasonably up to date. Unfortunately, "the difficulties of the times made large-scale alterations of the existing pages impracticable", and the bulk of the new material, mostly on work published since 1938, is collected in six additional chapters, occupying about a hundred pages. These chapters deal with a wide variety of topics falling under the general headings of hysteresis, ferromagnetic substances, weakly magnetic substances, radiofrequency spectroscopy, adiabatic demagnetization, and paramagnetic absorption and dispersion. In view of the author's notable contributions in some of these fields, particular interest is attached to his presentation of cognate work; and the chapter on radiofrequency spectroscopy provides almost the only recent short survey of the elegant techniques applied in determining nuclear moments. The treatment in the new chapters is, no doubt deliberately, somewhat uncritical ; and the 'adding on' of the miscellaneous new material inevitably leads to some lack of coherence in the book. It is much to be hoped that conditions will later enable the author to reshape the book into an artistic whole. For the present, however, many readers will be most grateful to the author for collecting together so much interesting information about recent work in magnetism.

E. C. S.

\section{The Romance of Rhodesia}

Being the Impressions of a Sight-seeing Tour to Southern and Northern Rhodesia via Seychelles, Mombasa, Zanzibar and Dar-es-Salaam. By Ardaser Sorabjee $\mathrm{N}$. Wadia. Pp. xiv $+146+16$ plates. (London : J. M. Dent and Sons, Ltd., 1947.) $21 s$. net.

N. WADIA'S ready pen has this time been 1 turned to describe a tourist trip to Rhodesia that was made before the War. He departed rarely from the conventional tourist route, and his brief sketch contains little that is new in factual information. Mr. Wadia touches frankly, however, on many of the problems that Rhodesia and other parts of Africa have to face. Thus he has reflexions on racial discrimination, the colour problem, the scope of missionary endeavour, and especially of the problem of Indians in South Africa. Generally he is critical of existing relations between races, but supports British rule. His eriticisms are worthy of attention. The book is beautifully illustrated. 